\title{
Heart Failure and Cognitive Impairment in the Atherosclerosis Risk in Communities (ARIC) Study
}

\author{
Lucy S. Witt, MD, MPH' , Jason Rotter, MHS', Sally C. Stearns, PhD ${ }^{3}$, \\ Rebecca F. Gottesman, MD, PhD4, Anna M. Kucharska-Newton, PhD, MPH', \\ A. Richey Sharrett, MD ${ }^{6}$, Lisa M. Wruck, $P h D^{7}$, Jan Bressler, $P h D^{8}$, Carla A. Sueta, MD, PhD ${ }^{9}$, and \\ Patricia P. Chang, MD, $M H S^{9}$
}

\begin{abstract}
'Department of Hospital Medicine, Atlanta Veterans Affairs Medical Center, Decatur, GA, USA; '2Department of Health Policy \& Management, Gillings School of Global Public Health, The University of North Carolina at Chapel Hill, Chapel Hill, NC, USA; ${ }^{3}$ Cecil G. Sheps Center for Health Services Research, The University of North Carolina at Chapel Hill, Chapel Hill, NC, USA; ${ }^{4}$ Department of Neurology, Johns Hopkins University School of Medicine, Baltimore, MD, USA; ${ }^{5}$ Department of Epidemiology, Gillings School of Global Public Health, The University of North Carolina at Chapel Hill, Chapel Hill, NC, USA; ${ }^{6}$ Department of Epidemiology, Johns Hopkins Bloomberg School of Public Health, Baltimore, MD, USA; ${ }^{7}$ Duke Clinical Research Institute, Duke University, Durham, NC, USA; ${ }^{8}$ Human Genetics, and Environmental Sciences, University of Texas Health School of Public Health Department of Epidemiology, Austin, TX, USA; ${ }^{9}$ Department of Medicine, University of North Carolina at Chapel Hill, Chapel Hill, NC, USA.
\end{abstract}

BACKGROUND: Previous studies suggest that heart failure $(\mathrm{HF})$ is an independent risk factor for cognitive decline. A better understanding of the relationship between HF, cognitive status, and cognitive decline in a communitybased sample may help clinicians understand disease risk. OBJECTIVE: To examine whether persons with $\mathrm{HF}$ have a higher prevalence of cognitive impairment and whether persons developing HF have more rapid cognitive decline. DESIGN: This observational cohort study of American adults in the Atherosclerosis Risk in Communities (ARIC) study has two components: cross-sectional analysis examining the association between prevalent $\mathrm{HF}$ and cognition using multinomial logistic regression, and change over time analysis detailing the association between incident HF and change in cognition over 15 years. PARTICIPANTS: Among visit 5 (2011-2013) participants (median age 75 years), 6495 had neurocognitive information available for cross-sectional analysis. Change over time analysis examined the 5414 participants who had cognitive scores and no prevalent HF at visit 4 (1996-1998). MEASUREMENTS: The primary outcome was cognitive status, classified as normal, mild cognitive impairment [MCI], and dementia on the basis of standardized cognitive tests (delayed word recall, word fluency, and digit symbol substitution). Cognitive change was examined over a 15year period. Control variables included socio-demographic, vascular, and smoking/drinking measures.

RESULTS: At visit 5, participants with HF had a higher prevalence of dementia (adjusted relative risk ratio $[\mathrm{RRR}]=1.60$ [95\% CI 1.13, 2.25]) and MCI $(\mathrm{RRR}=1.36$ $[1.12,1.64])$ than those without HF. A decline in cognition

Data from this manuscript was presented at American Heart Association Scientific Sessions on November 13, 2016.

Electronic supplementary material The online version of this article (https://doi.org/10.1007/s11606-018-4556-x) contains supplementary material, which is available to authorized users.

Received December 1, 2017

Revised March 26, 2018

Accepted June 27, 2018

Published online July 20, 2018 between visits 4 and 5 was -0.07 standard deviation units $[-0.13,-0.01]$ greater among persons who developed HF compared to those who did not. Results did not differ by ejection fraction.

CONCLUSION: HF is associated with neurocognitive dysfunction and decline independent of other co-morbid conditions. Further study is needed to determine the underlying pathophysiology.

KEY WORDS: heart failure; cognitive impairment; dementia; cognitive decline.

J Gen Intern Med 33(10):1721-8

DOI: $10.1007 / \mathrm{s} 11606-018-4556-x$

(C) Society of General Internal Medicine 2018

\section{INTRODUCTION}

Over five million Americans suffer from heart failure (HF). ${ }^{1}$ Approximately $25-50 \%$ of patients with HF are estimated to have cognitive impairment, commonly reporting deficits in attention, reduced executive function, slowed processing speed, and memory loss. ${ }^{2-4}$ Mild deficits can be classified as mild cognitive impairment (MCI), while the American Psychiatric Association defines dementia as a multidomain impairment in cognitive ability that interferes with everyday activities. ${ }^{5}$ Cerebral hypo-perfusion due to decreased cardiac output and HF-related cardioembolic stroke may be mechanisms for the reported association of HF with cognitive impairment. 6,7 Atherosclerotic vascular disease, whether from the cumulative exposure to cardiovascular risk factors (elevated glucose and blood pressure) or subclinical atherosclerosis, affects cognitive function and is often related to $\mathrm{HF}^{8-15}$ Furthermore, alterations in circulatory hormones due to a failing heart or medication side effects may also lead to HF-related cognitive impairment. ${ }^{16-18}$ Given that the risk factors for atherosclerosis, HF, and stroke (such as hypertension, diabetes, and smoking) are intertwined and overlapping, it is 
difficult to analyze the root cause of this HF-cognition association. Compounding this low left ventricular ejection fraction (EF) may be associated with worse cognitive performance, particularly in the presence of lower mean arterial pressure and the decompensated HF state. ${ }^{19-21}$

The Atherosclerosis Risk in Communities (ARIC) study cohort provides an opportunity to elucidate the association between HF and cognitive dysfunction. Our study examines whether those with HF have a higher prevalence of dementia or MCI compared to those without HF. To bolster our assessment and identify more subtle changes in mental status, we also investigate the association between incident HF and change in cognitive function over time.

\section{METHODS}

This study uses multivariate regression to assess the relationship between HF and neurocognitive status in older adults through two analyses: (1) a cross-sectional analysis examining the association of HF with a categorical measure of cognition at a single point in time and (2) the association between onset of $\mathrm{HF}$ and the change in a continuous measure of cognition over a 15 -year period.

\section{Study Population: The ARIC Study}

The ARIC study is a biracial cohort of 15,792 men and women, 45-64 years of age in 1987-1989, selected through population sampling from: Jackson, Mississippi; Forsyth County, North Carolina; suburbs of Minneapolis, Minnesota; and Washington County, Maryland. The ARIC study provides longitudinal data on risk factors and outcomes associated with atherosclerosis. Incident HF, coronary heart disease, and stroke were determined from annual follow-up phone interviews with cohort participants and review of hospitalization records. Risk factors were measured at in-person examinations. Neurocognitive information from the two most recent in-person examinations, visit 5 (2011-2013) and visit 4 (1996-1998), was used for this analysis. Only blacks were enrolled in Jackson, and extremely few blacks were enrolled in Minneapolis and Washington County. We therefore included only the majority race at each site except for Forsyth County, which included both White and Black participants. This represents standard protocol for the ARIC study. ${ }^{22}$

\section{Study Sample}

Of the estimated 10,036 cohort members alive in 2011, 6538 individuals participated in visit 5 (2011-2013). Information on neurocognitive status was available for 6495 participants, who comprise the study sample for the cross-sectional analysis. For the analysis of change in neurocognitive status over time, 5414 participants who had cognition scores from both visit 4 and visit 5 and no indication of prevalent HF at visit 4 (19961998) were examined.

\section{Outcomes}

In our cross-sectional analysis, visit 5 participants were classified as having normal cognition, MCI, or dementia. Classification was based on a computer-derived algorithm with physician review. The computer algorithm combined data from multiple domains including scoring on standardized assessments of delayed word recall (DWR), word fluency test (WFT), and digit symbol substitution test (DSST). Memory, executive functioning, and attention were similarly analyzed, as were data reflecting orientation, judgment, and personal care. A final component assessed functioning in everyday life as reported by participant and, when indicated, a knowledgeable informant using the Clinical Dementia Rating interview. Physician reviewers adjudicated the computer-derived algorithm to ensure appropriate neurocognitive designation. This evaluation has been described elsewhere. ${ }^{23,} 24$

The assessment of change in cognition over time examined only the subset of participants without prevalent HF at visit 4 (Fig. 1). Scores on three neurocognitive tests (DWR, WFT, DSST) were combined and standardized to visit 2 scores (1996-1998). ${ }^{15}$ Performance on these tests was assessed at visit 4 and again at visit 5 (approximately 15 years apart). ${ }^{25,26}$ Cognitive change for those who developed HF between visit 4 and visit 5 was compared to those who did not. A separate analysis was conducted to observe cognitive change over time involving only those participants with normal cognition at visit 4. Details regarding cognitive status assessments in ARIC have been published elsewhere. ${ }^{27}$

\section{Exposure and Covariates}

Prevalent $\mathrm{HF}$ at visit 5 was classified by having at least one of the following: an adjudicated diagnosis of HF, International Classification of Disease, 9th Revision, Clinical Modification (ICD-9-CM) discharge code of 428.X in first position not overruled by a physician, self-reported HF or self-report of HF medication with pro-BNP greater than $125 \mathrm{pg} / \mathrm{mL}$, or subsequent self-report of HF or HF medication (defined as medications participants reported taking for the treatment of HF). Prevalent HF at visit 4, which eliminated participants from the longitudinal analysis, was identified by at least one of the following: ICD-9 discharge code 428 from prior hospitalizations; self-report of $\mathrm{HF}$ at visit 4; or self-reported medication for $\mathrm{HF}$ at visit 4 . HF with preserved $\mathrm{EF}$ (HFpEF) was defined as $\mathrm{EF} \geq 50 \%$, with reduced $\mathrm{EF}$ (HFrEF) defined as $\mathrm{EF}$ $<50 \%$ based on echocardiogram at visit 5 . These definitions have been validated previously. ${ }^{28-30}$ Incident HF between visits 4 and 5, used in the longitudinal analysis, was identified by hospital heart failure-specific discharge diagnosis ICD-9 codes during that follow-up interval.

Covariates included information on demographics (age, gender, study site, education) as well as marital status, individual socioeconomic status, behaviors (drinking and smoking), and selected diagnoses (depression, diabetes, hypertension, myocardial infarction, atrial fibrillation, and stroke). A 


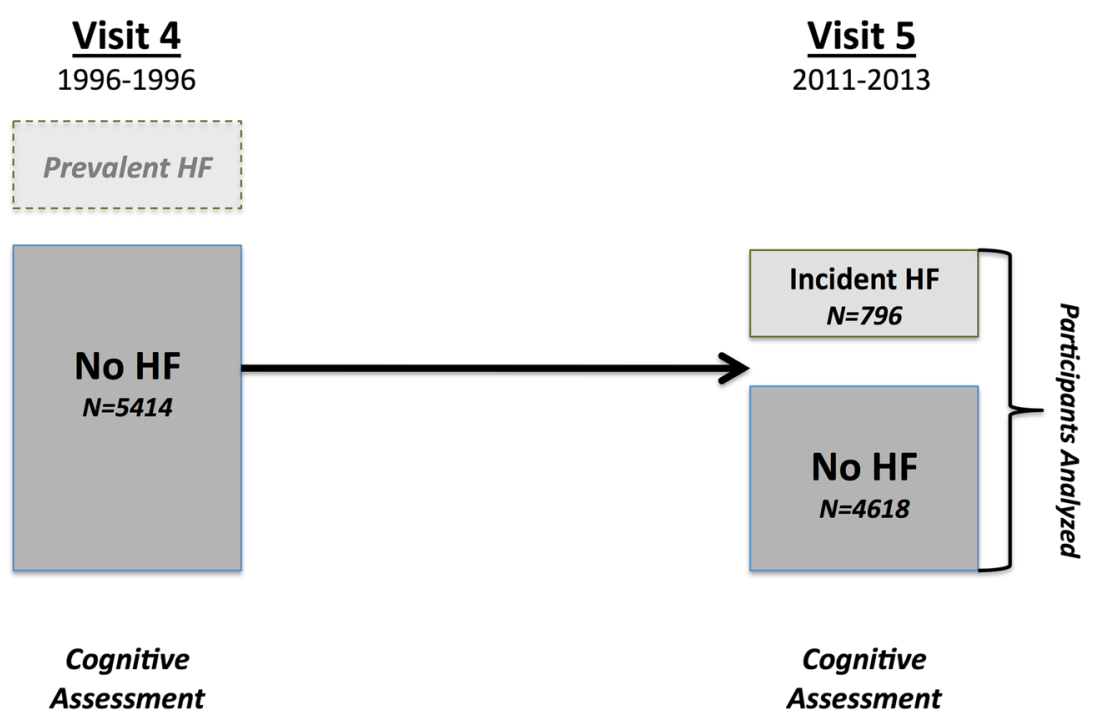

Fig. 1 Comparing the change in neurocognitive ability over time between those who developed heart failure and those who did not. This figure graphically describes the participants analyzed in the change over time analysis. Only those without HF at visit 4 were examined. Those who subsequently developed HF within the 15-year period were compared to those who did not develop HF.

Charlson co-morbidity score was included to account for debility from other diseases. ${ }^{31}$ Hypertension was defined as systolic blood pressure (SBP) greater than $140 \mathrm{mmHg}$, a diastolic blood pressure (DBP) greater than $90 \mathrm{mmHg}$, or if the participant reported taking anti-hypertensive medication. Participants were considered diabetic if they were taking any diabetes medication, self-reported physician diagnosis of diabetes, or had a hemoglobin A1c greater than $6.5 \%$ at a study visit. Diagnoses of prevalent stroke (CVA), coronary heart disease (CHD), atrial fibrillation (AF), and myocardial infarction (MI) were ascertained from hospital records, physicians, participants, and their families throughout follow-up using standardized interviews, questionnaires, and surveillance methods previously described elsewhere. ${ }^{32-34}$ All covariates were ascertained at visit 5, except education, occupation, race, and gender, which were reported at visit 1 . The MacArthur Scale of Subjective Social Status assessed social standing relative to peers on a scale from 1 to $10 .^{35} \mathrm{~A}$ continuous measure of depression was constructed from 12 questions representing a shorter but validated form of the CES-D depression symptoms index. ${ }^{36,37}$

\section{Statistical Analysis}

To assess the cross-sectional association between HF and neurocognitive status at visit 5 , multinomial logistic models estimated relative risk ratios (RRR) for the three-category neurocognitive outcome variable (normal, $\mathrm{MCI}$, and dementia). To assess the association between onset of HF and the change in neurocognitive status between visits 4 and 5, ordinary least squares models were used. For both the crosssectional and change over time models, dichotomous measures of $\mathrm{HF}$ and $\mathrm{HF}$ ejection fraction type (reduced versus preserved $\mathrm{EF}$ ) were used. All models included an interaction of HF with age and controlled for age, gender, ARIC site/race, education, marital status, the McArthur scale, hypertension, diabetes, stroke, AF, CES-D score, Charlson co-morbidity score, smoking status, and drinking status.

To account for non-participation in visit 5 (estimated at nearly $40 \%$ ), inverse probability of attrition weighting (IPAW) was used as a sub-analysis (online appendix). For this, the probability of non-participation was predicted as a function of complete case variables (age, gender, race, study site, education, smoking status, and occupation). Multiple imputation was used in all models to allow for a complete analysis when covariate information was not directly available. All data analyses were performed using Stata v14 (StataCorp. 2015. Stata Statistical Software: Release 14. College Station, TX: StataCorp LP).

\section{RESULTS}

Table 1 presents clinical characteristics for participants who attended visit 5. Included cohort members had a mean age of 76 years (SD 5.3) and most were female (59\%). A total of 953 $(15 \%)$ individuals had prevalent $\mathrm{HF}$ at visit 5 , of whom $38 \%$ were classified as having dementia or MCI (compared to $24 \%$ of those without HF). The sample included only 105 cases of HFrEF, $11 \%$ of those with HF, while 184 (19\%) individuals with HF were missing ejection fraction data. Compared to those with HF, those without HF $(n=5542)$ were more likely to be female and better educated. They were also more likely to be current drinkers. Among those with HFrEF, the average EF was $40 \%$ (SD 6.5) and only 33 had EF $\leq 35 \%$. Those with HF had worse scores on standardized tests (DWR, WFT, DSST) at visit 5 compared to those without HF even when comparing only those with a diagnosis of dementia or MCI to each other (online appendix). 
Table 1 Clinical Characteristics by Heart Failure Type: the Atherosclerosis Risk in Communities (ARIC) Study, Visit 5 (20112013)

\begin{tabular}{|c|c|c|c|c|}
\hline & $\begin{array}{l}\text { Total } \\
(N= \\
6495)\end{array}$ & $\begin{array}{l}\text { No HF } \\
(N= \\
5542)\end{array}$ & $\begin{array}{l}\text { HF } \\
(N= \\
953)\end{array}$ & $\overline{p^{\dagger}}$ \\
\hline Visit 5 age, mean(SD) & $\begin{array}{l}76.3 \\
(5.3)\end{array}$ & $76.1(5.2)$ & $\begin{array}{l}77.8 \\
(5.5)\end{array}$ & $<0.001$ \\
\hline Gender, $N(\%)$ & & & & $<0.001$ \\
\hline Female & $\begin{array}{l}3823 \\
(58.9 \%)\end{array}$ & $\begin{array}{l}3325 \\
(60.0 \%)\end{array}$ & $\begin{array}{l}498 \\
(52.3 \%)\end{array}$ & \\
\hline $\begin{array}{l}\text { Site/race, } N(\%) \\
\text { Minneapolis (White) }\end{array}$ & & & & $<0.001$ \\
\hline & $\begin{array}{l}1325 \\
(20.4 \%)\end{array}$ & $(21.3 \%)$ & $(15.0 \%)$ & \\
\hline Washington (White) & $\begin{array}{l}1416 \\
(21.8 \%)\end{array}$ & $\begin{array}{l}1082 \\
(19.5 \%)\end{array}$ & $\begin{array}{l}334 \\
(35.0 \%)\end{array}$ & \\
\hline Forsyth (White) & $\begin{array}{l}1901 \\
(29.3 \%)\end{array}$ & $\begin{array}{l}1686 \\
(30.4 \%)\end{array}$ & $\begin{array}{l}215 \\
(22.6 \%)\end{array}$ & \\
\hline Forsyth (Black) & $\begin{array}{l}1750 \\
(26.9 \%)\end{array}$ & $\begin{array}{l}1504 \\
(27.1 \%)\end{array}$ & $\begin{array}{l}246 \\
(25.8 \%)\end{array}$ & \\
\hline Jackson (Black) & $\begin{array}{l}103 \\
(1.6 \%)\end{array}$ & 88 (1.6\%) & $\begin{array}{l}15 \\
(1.6 \%)\end{array}$ & \\
\hline $\begin{array}{l}\text { MacArthur scale of } \\
\text { subjective social } \\
\text { status, mean (SD)* }\end{array}$ & $5.8(1.7)$ & $5.9(1.7)$ & $5.4(1.9)$ & $<0.001$ \\
\hline $\begin{array}{l}\text { Education level, } \\
N(\%)^{*}\end{array}$ & & & & $<0.001$ \\
\hline $\begin{array}{l}\text { Less than high } \\
\text { school (HS) }\end{array}$ & $\begin{array}{l}982 \\
(15.1 \%)\end{array}$ & $\begin{array}{l}716 \\
(12.9 \%)\end{array}$ & $\begin{array}{l}266 \\
(27.9 \%)\end{array}$ & \\
\hline At least high school & $\begin{array}{l}2696 \\
(41.5 \%)\end{array}$ & $\begin{array}{l}2324 \\
(41.9 \%)\end{array}$ & $\begin{array}{l}372 \\
(39.0 \%)\end{array}$ & \\
\hline $\begin{array}{l}\text { At least some post } \\
\text { HS }\end{array}$ & $\begin{array}{l}2806 \\
(43.2 \%)\end{array}$ & $\begin{array}{l}2493 \\
(45.0 \%)\end{array}$ & $\begin{array}{l}313 \\
(32.8 \%)\end{array}$ & \\
\hline $\begin{array}{l}\text { Visit } 5 \text { marital status, } \\
N(\%)\end{array}$ & & & & $<0.001$ \\
\hline Married & $\begin{array}{l}4147 \\
(63.8 \%)\end{array}$ & $\begin{array}{l}3615 \\
(65.2 \%)\end{array}$ & $\begin{array}{l}532 \\
(55.8 \%)\end{array}$ & \\
\hline Formerly married & $\begin{array}{l}2226 \\
(34.3 \%)\end{array}$ & $\begin{array}{l}1818 \\
(32.8 \%)\end{array}$ & $\begin{array}{l}408 \\
(42.8 \%)\end{array}$ & \\
\hline Never married & $\begin{array}{l}122 \\
(1.9 \%)\end{array}$ & $\begin{array}{l}109 \\
(2.0 \%)\end{array}$ & $\begin{array}{l}13 \\
(1.4 \%)\end{array}$ & \\
\hline \multicolumn{5}{|l|}{$\begin{array}{l}\text { Prevalent co- } \\
\text { morbidities at visit } 5, \\
N(\%)\end{array}$} \\
\hline Hypertension* & $\begin{array}{l}4793 \\
(73.8 \%)\end{array}$ & $\begin{array}{l}3979 \\
(71.8 \%)\end{array}$ & $\begin{array}{l}814 \\
(85.4 \%)\end{array}$ & \\
\hline $\mathrm{CHD}^{*}$ & $\begin{array}{l}966 \\
(14.9 \%)\end{array}$ & $\begin{array}{l}554 \\
(10.0 \%)\end{array}$ & $\begin{array}{l}412 \\
(43.2 \%)\end{array}$ & \\
\hline Diabetes & $\begin{array}{l}2229 \\
(34.3 \%)\end{array}$ & $\begin{array}{l}1725 \\
(31.1 \%)\end{array}$ & $\begin{array}{l}504 \\
(52.9 \%)\end{array}$ & \\
\hline Atrial fibrillation* & $\begin{array}{l}595 \\
(9.2 \%)\end{array}$ & $\begin{array}{l}350 \\
(6.3 \%)\end{array}$ & $\begin{array}{l}245 \\
(25.7 \%)\end{array}$ & \\
\hline Stroke* & $\begin{array}{l}266 \\
(4.1 \%)\end{array}$ & $\begin{array}{l}159 \\
(2.9 \%)\end{array}$ & $\begin{array}{l}107 \\
(11.2 \%)\end{array}$ & \\
\hline $\begin{array}{l}\text { CES-depression } \\
\text { scale, mean (SD)* }\end{array}$ & $3.2(3.1)$ & $3.0(3.0)$ & $4.1(3.5)$ & $<0.001$ \\
\hline $\begin{array}{l}\text { Charlson co- } \\
\text { morbidity score (SD) }\end{array}$ & $0.8(1.8)$ & $0.7(1.5)$ & $1.6(2.8)$ & $<0.001$ \\
\hline $\begin{array}{l}\text { Visit } 5 \text { smoking } \\
\text { status, } N(\%)^{*}\end{array}$ & & & & 0.66 \\
\hline Current smoker & $\begin{array}{l}323 \\
(5.0 \%)\end{array}$ & $\begin{array}{l}278 \\
(5.0 \%)\end{array}$ & $\begin{array}{l}45 \\
(4.7 \%)\end{array}$ & \\
\hline Never smoker & $\begin{array}{l}1794 \\
(27.6 \%)\end{array}$ & $\begin{array}{l}1520 \\
(27.4 \%)\end{array}$ & $\begin{array}{l}274 \\
(28.8 \%)\end{array}$ & \\
\hline Former smoker & $\begin{array}{l}4364 \\
(67.2 \%)\end{array}$ & $\begin{array}{l}3733 \\
(67.4 \%)\end{array}$ & $\begin{array}{l}631 \\
(66.2 \%)\end{array}$ & \\
\hline $\begin{array}{l}\text { Visit } 5 \text { drinking } \\
\text { status, } N(\%)\end{array}$ & & & & $<0.001$ \\
\hline Current drinker & $\begin{array}{l}2966 \\
(45.7 \%)\end{array}$ & $\begin{array}{l}2665 \\
(48.1 \%)\end{array}$ & $\begin{array}{l}301 \\
(31.6 \%)\end{array}$ & \\
\hline Former drinker & $\begin{array}{l}1800 \\
(27.7 \%)\end{array}$ & $\begin{array}{l}1463 \\
(26.4 \%)\end{array}$ & $\begin{array}{l}337 \\
(35.4 \%)\end{array}$ & \\
\hline Never drinker & $\begin{array}{l}1302 \\
(20.0 \%)\end{array}$ & $\begin{array}{l}1088 \\
(19.6 \%)\end{array}$ & $\begin{array}{l}214 \\
(22.5 \%)\end{array}$ & \\
\hline $\begin{array}{l}\text { Visit } 5 \text { neurocognitive } \\
\text { status, } N(\%)^{*}\end{array}$ & & & & $<0.001$ \\
\hline
\end{tabular}

Table 1. (continued)

\begin{tabular}{|c|c|c|c|c|}
\hline & $\begin{array}{l}\text { Total } \\
(N= \\
6495)\end{array}$ & $\begin{array}{l}\text { No HF } \\
(N= \\
5542)\end{array}$ & $\begin{array}{l}\text { HF } \\
(N= \\
953)\end{array}$ & $p^{\dagger}$ \\
\hline Dementia & $\begin{array}{l}341 \\
(5.3 \%)\end{array}$ & $\begin{array}{l}241 \\
(4.3 \%)\end{array}$ & $\begin{array}{l}100 \\
(10.5 \%)\end{array}$ & \\
\hline $\begin{array}{l}\text { Mild cognitive } \\
\text { impairment }\end{array}$ & $\begin{array}{l}1366 \\
(21.0 \%)\end{array}$ & $\begin{array}{l}1106 \\
(20.0 \%)\end{array}$ & $\begin{array}{l}260 \\
(27.3 \%)\end{array}$ & \\
\hline Normal & $\begin{array}{l}4724 \\
(72.7 \%)\end{array}$ & $\begin{array}{l}4143 \\
(74.8 \%)\end{array}$ & $\begin{array}{l}581 \\
(61.0 \%)\end{array}$ & \\
\hline $\begin{array}{l}\text { Visit } 5 \text { cognitive } \\
\text { score, mean }(\mathrm{SD})^{*}\end{array}$ & $\begin{array}{l}-0.57 \\
(1.01)\end{array}$ & $\begin{array}{l}-0.50 \\
(0.99)\end{array}$ & $\begin{array}{l}-1.02 \\
(1.01)\end{array}$ & $<0.001$ \\
\hline $\begin{array}{l}\text { Visit } 4 \text { cognitive } \\
\text { score, mean }(\mathrm{SD})^{*}\end{array}$ & $\begin{array}{l}0.18 \\
(0.92)\end{array}$ & $\begin{array}{l}0.24 \\
(0.90)\end{array}$ & $\begin{array}{l}-0.20 \\
(0.95)\end{array}$ & $<0.001$ \\
\hline
\end{tabular}

*Missing: MacArthur SES (259), education, ${ }^{11}$ hypertension (92), CHD (110), Atrial fibrillation (455), stroke, ${ }^{10}$ CES-D (138), smoking, ${ }^{14}$ drinking (427), neurocog status (64), V5 cognitive score(627), V4 cognitive score (644)

${ }^{\dagger} p$ values are calculated via t test and chi-squared tests for continuous and categorical covariates, respectively

\section{Heart Failure and Cognitive Impairment at Visit 5}

Table 2 provides unadjusted and multivariate-adjusted results of our analysis. With adjustment for co-morbidities, individuals with prevalent HF were more likely to have dementia $(\mathrm{RRR}=1.60[95 \% \mathrm{CI} 1.13,2.25])$ and $\mathrm{MCI}(\mathrm{RRR}=1.36$ $[1.12,1.64])$ compared to those without HF. When separating HF by ejection fraction type, we observed a similar effect size but with limited ability to detect a statistically significant difference in cognition in the HFrEF group, potentially due to small sample size (online appendix).

Table 2 Relative Risk Ratios of Dementia and Mild Cognitive Impairment for Those with Heart Failure Compared to Those Without

RRR of dementia (vs. normal cognition)

$\begin{array}{llll} & \begin{array}{l}\text { Model 1 } \\ \text { (unadjusted) }\end{array} & \begin{array}{l}\text { Model 2* } \\ \text { (limited } \\ \text { controls) }\end{array} & \begin{array}{l}\text { Model 3 } \\ \text { (full controls) }\end{array} \\ \text { HF vs. No } & 2.96[2.31,3.79] & 2.57[1.89, & 1.6[1.13, \\ \text { HF } & & 3.47] & 2.25]\end{array}$

RRR of MCI (vs. normal cognition)

$$
\begin{aligned}
& \text { Model } 1 \\
& \text { (unadjusted) }
\end{aligned}
$$

HF vs. No $1.68[1.43,1.97]$ $\mathrm{HF}$

This table shows the relative risk ratio of those with $H F$ to have dementia or MCI compared to those without. Three models are presented; the first is unadjusted, second adjusted for limited controls, and the third adjusted for all controls

$R R R$ relative risk ratio, $H F$ heart failure, MCI mild cognitive impairment

*Controlled for age, gender, site/race

${ }^{+}$Controlled for age, gender, site/race, 3-category smoking status, 3category drinking status, 3-level education, 3-level marital status, McArthur SES scale, Charlson co-morbidity, hypertension, CHD, diabetes, atrial fibrillation, stroke 


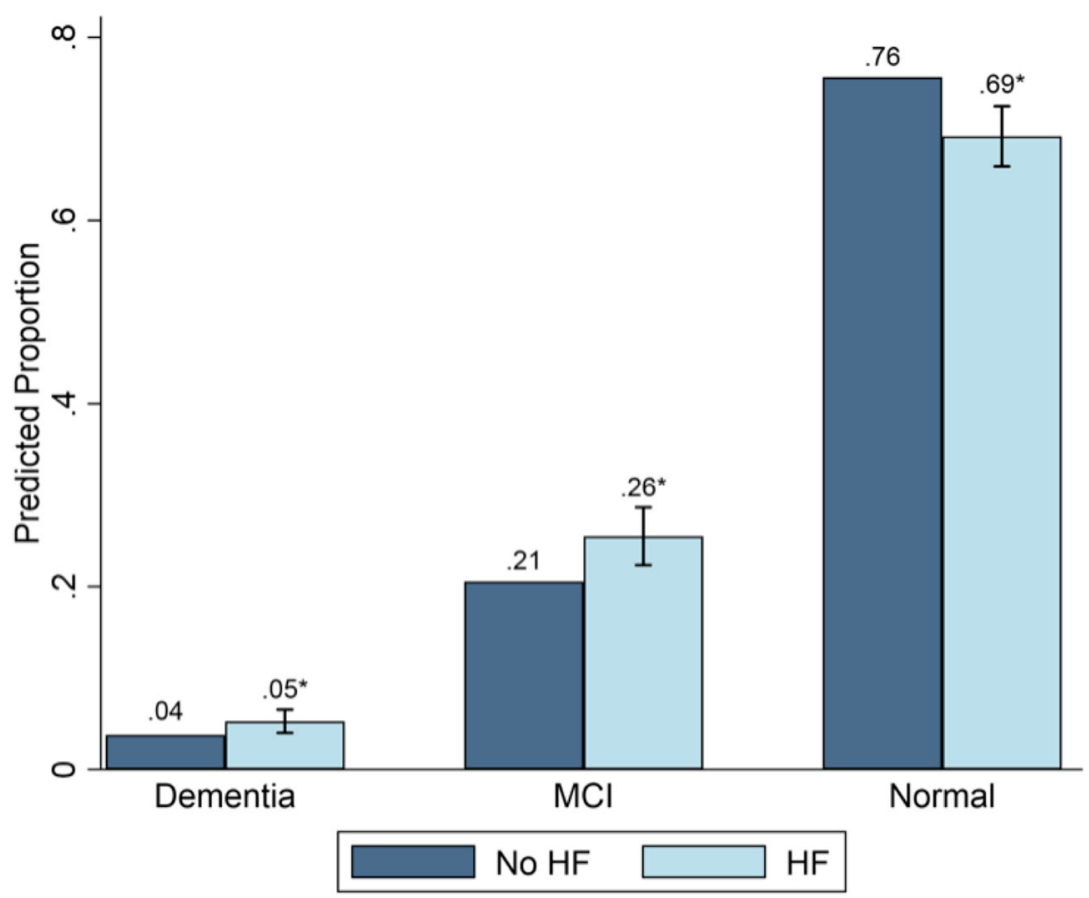

Fig. 2 Predicted Proportion of those with and without heart failure to have dementia, mild cognitive impairment, or normal cognition. This figure describes the predicted prevalence (PP) of dementia, mild cognitive impairment (MCI), or normal cognition at visit 5 for those participants who developed heart failure compared to those who did not. Error bars represent the $95 \%$ confidence interval in reference to those without heart failure. * $p<0.05$ compared to no HF. HF heart failure, MCI mild cognitive impairment. All models control for age, gender, ARIC site/race, education, marital status, McArthur Financial SES ladder, hypertension, diabetes, stroke, atrial fibrillation, CES-D score Charlson comorbity score, smoking status, and drinking status. Models imputed missing covariates using multiple imputation (see Table 1) $(M=50)$.

Figure 2 shows the multivariate-adjusted prevalence of dementia, MCI, and normal cognition for those with and without HF. Error bars display 95\% confidence intervals for the differences compared to persons without HF. Although small sample size limits the analysis in those with HFrEF, cognition was

Table 3 Change in Cognition by HF Type Compared to Persons Without Heart Failure Between Visit 4 (1996-1998) and Visit 5 (2011-2013): The Atherosclerosis Risk in Communities Study

Change in global $z$ score (V4

to V5)

\begin{tabular}{llll}
\hline & $\begin{array}{l}\text { Model 1 } \\
\text { (unadjusted) }\end{array}$ & $\begin{array}{l}\text { Model 2* (limited } \\
\text { controls) }\end{array}$ & $\begin{array}{l}\text { Model 3 } \\
\text { controls) }\end{array}$ \\
HF vs. & $-0.13[-0.19,-$ & $-0.11[-0.17,-$ & $-0.07[-0.13$, \\
No HF & $0.07]$ & $0.05]$ & $-0.01]$ \\
\hline
\end{tabular}

This table shows the adjusted change in mean standardized $z$ score on three well-studied neurocognitive tests (delayed word recall, digit symbol substitution, and word fluency). Scores were combined and standardized to visit 2 scores (1990-1992). This difference is interpreted as a 15-year change in standard deviation units (SDU) for those with $H F$ as compared to those without

$N=5414$; All models centered at mean age. Models imputed missing covariates using multiple imputation (see Table 1)

HF heart failure

*Controlled for age, gender, site/race

${ }^{+}$Controlled for age, gender, site/race, 3-category smoking status, 3category drinking status, 3-level education, 3-level marital status, McArthur SES scale, Charlson co-morbidity, hypertension, CHD, diabetes, atrial fibrillation, stroke nominally worse for participants with both $\mathrm{HFpEF}$ and $\mathrm{HFrEF}$ as compared to those without HF (online appendix).

\section{Incident Heart Failure and Change in Cognition Over Time}

Table 3 displays the difference in the adjusted change in neurocognitive scores between visit 4 and visit 5 for those who developed HF $(n=796)$ during that period. We observed a significantly greater cognitive decline among persons who developed $\mathrm{HF}$ over the 15-year period (mean standardized $z$ score of -0.50 at visit 4 to -1.02 at visit 5) compared to those who did not develop HF (mean score of 0.24 at visit 4 to -0.20 at visit 5), with an adjusted difference of -0.07 , (95\% CI -0.13 , $-0.01)$. This difference is interpreted as a 15 -year change in standard deviation units (SDU) for those with HF as compared to those without. This change, when compared to normal aging, represents an estimated additional 1.5 years of cognitive decline. $^{38,}{ }^{39}$ When analyzing change by HF type, the magnitude and direction of neurocognitive decline was similar with limited power to detect differences among those with HFrEF due to small sample size (online appendix). A post hoc analysis examining only those participants with normal cognition at visit 4 revealed that participants who developed incident HF between visits 4 and 5 had a greater decline in cognition (mean standardized $z$ score of -0.06 ) compared to those who did not develop HF (online appendix). 
Additional analyses were conducted to examine potential effect measure modification of selected diseases, including $\mathrm{AF}, \mathrm{CHD}$, hypertension, and stroke, on the association of $\mathrm{HF}$ with change in cognitive status. No significant interaction was identified between these diagnoses and cognitive impairment in any HF group.

\section{DISCUSSION}

Heart failure is associated with an increased prevalence of dementia and mild cognitive impairment independent of conventional risk factors for either diagnosis. Similarly, those participants who developed incident HF showed greater cognitive decline over the same period as compared to those who did not develop HF. Given that this study controls for disease states proposed to contribute to cognitive dysfunction in the HF population (such as stroke, hypertension, diabetes, and depression), these findings suggest that HF itself may directly predispose individuals to a range of cognitive impairments.

The mechanism of this association is currently unknown and cannot be explained purely on the basis of decreased EF, as those with HFrEF showed similar results to those with HFpEF in both the cross-sectional and the change over time analyses. The relationship between $\mathrm{EF}$ and cognitive function has been described as nonlinear, with a steeper association between EF and decreased cognition at lower levels of EF than at higher levels, ${ }^{20,}{ }^{40}$ however, our small sample of HFrEF participants limits our analysis of this relationship, especially since only $3.5 \%$ had LVEF $\leq 35 \%$. Proposed pathways connecting HF to cognitive decline include cerebral atrophy from hypo-perfusion, infarction due to decreased blood flow, subclinical cardioembolic phenomena, and an association between natriuretic peptides and the deposition of amyloid plaques in the brain. ${ }^{16,17,41,42}$ Other possible causes include the interplay between decreased cardiac output and previously described co-morbidities including microvascular damage from diabetes, vascular damage from hypertension, and arterial disease. ${ }^{2,} 43,{ }^{44}$ Finally, the association might be noncausal, e.g., the result of confounding by the use of certain medications. The relationship between HF and cognitive decline is possibly bidirectional as those with HF may suffer cognitive decline as shown in our study; however, baseline poor cognition may lead to poor medication adherence for chronic diseases such as HTN and CHD further pre-disposing them to $\mathrm{HF}^{45}$

Previous studies have described a similar relationship between $\mathrm{HF}$ and cognitive impairment. Jefferson et al. examined a small cohort of elderly individuals $(n=72)$ and found that those with worse executive functioning were more likely to have low cardiac output. ${ }^{19}$ When examining a cohort of decompensated HF patients $(n=20)$ compared to healthy controls, Kindermann and colleagues noted worse cognition in those with HF. ${ }^{21}$ Gottesman and colleagues examined 234 individuals with coronary arterial disease and found that those with lower EF had lower global functioning scores and worsened motor function. ${ }^{20} \mathrm{~A}$ systematic review published in 2007 by Vogels et al. pooled analyses of case-control studies examining almost 3000 patients with HF. This analysis showed that patients with HF had increased prevalence of cognitive impairment (odds ratio 1.62, 95\% CI 1.48-1.79) than those without HF. ${ }^{17}$ All these studies suggest a strong crosssectional relationship between HF and cognitive impairment, though the studies varied in their control for cardiovascular risk factors and other potential confounders.

Although prior longitudinal studies have demonstrated the relationship between more pronounced cognitive decline and heart failure, our multi-center ARIC cohort study is unique in its combination of size, detailing of cognitive status, and its lengthy follow-up of over 15 years. ${ }^{46}$ All elderly participants in this large cohort were originally recruited at home and assessed in the ARIC field centers. Thus, this analysis refers to a group of individuals most of whom were healthy enough to attend nearly daylong in-person visits. Also, because of our unique outpatient setting, the observed association between $\mathrm{HF}$ and cognitive impairment is less likely to be confounded by delirium or situational depression, which was noted in studies consisting primarily of hospitalized patients. ${ }^{17}$ Additionally, our study's neuropsychological assessment included a wide range of cognitive abilities: executive functioning, spatial reasoning, and ability to perform activities of daily living. The extensive neuropsychological evaluations undertaken in this analysis and examination of an elderly population from the community is only matched by European studies including the Rotterdam Study and Three-City Study. Furthermore, ARIC includes a more racially diverse population than these other analyses. ${ }^{47,}{ }^{48}$ Our study details a clear association between HF and MCI as well as dementia, which is less well described in current literature.

Several limitations pertain to this study. Importantly, although we examine a wider range of health and disease than is possible in hospital-based studies, due to the physical and temporal requirements of the comprehensive in-person examination, ARIC participants who completed visit 5 were inherently healthier than those who refused or were unable to participate. This healthy-participant effect likely contributes to the low observed prevalence of dementia and limits our ability to examine the very sickest HF patients or those with severe dementia. Additionally, our analysis examines the relationship of the change in cognition over time and concurrent development of HF. While this design works to avoid confounding by factors which are stable over time in participants (such as educational or intellectual background), the data did not allow us to determine which occurred first (cognitive decline or development of HF), so causal interpretations are not possible. Prior studies have demonstrated a predisposition to develop heart failure as cognitive function declines, and it is possible that this relationship is bidirectional which may falsely strengthen the observed relationship. ${ }^{27} \mathrm{HF}$ medications have also been proposed to interact with or contribute to 
cognitive decline. Only limited information was available regarding medication usage, adherence, and temporality between visits 4 and 5, limiting inclusion of potential medication effects in our analysis. Finally, the observational nature of the study means that we cannot be sure of freedom from residual unmeasured confounding.

Despite these limitations, this analysis highlights associations between HF and neurocognitive decline that cannot be explained by known and observed risk factors. These findings can aid clinicians when caring for HF patients and ensure they are attuned to the risk of cognitive decline associated with this disease. It also provides potential areas for further analysis and therefore intervention to prevent cognitive decline, whether by improved HF treatment, increasing cardiac output, or adjusting medications.

Future studies should aim to observe changes in cognitive function occurring after HF develops, with possible neurologic imaging and more detailed examinations of disease states that may contribute to cognitive decline. Similarly, potential differences in cognitive status among those with HFrEF as compared to those with HFpEF warrant additional investigation, given a potential relationship between cardiac output and cognitive decline.

Acknowledgments: The Atherosclerosis Risk in Communities Study is carried out as a collaborative study supported by National Heart, Lung, and Blood Institute contracts (HHSN268201100005C, HHSN $268201100006 \mathrm{C}$, HHSN $268201100007 \mathrm{C}$, HHSN $268201100008 \mathrm{C}$, HHSN $268201100009 \mathrm{C}$, HHSN $268201100010 \mathrm{C}$, HHSN268201100011C, and HHSN268201100012C). Neurocognitive data is collected by UO1 HL096812, HL096814, HL096899, HL096902, HL096917 with previous brain MRI examinations funded by R01-HL70825. Dr. Gottesman is supported by NIH/NIA grant K24 AG052573. We also thank Jo Ellen Rodgers, Pharm D for her insight and thoughtfulness. The authors thank the staff and participants of the ARIC study for their important contributions.

Corresponding Author: Lucy S. Witt, MD, MPH; Department of Hospital Medicine Atlanta Veterans Affairs Medical Center, Decatur, GA, USA (e-mail: lucyswitt@gmail.com).

\section{Compliance with Ethical Standards:}

Conflict of Interest: Rebecca Gottesman is an Associate Editor for the journal Neurology.

\section{REFERENCES}

1. Mozaffarian D, Benjamin EJ, Go AS, Arnett DK, Blaha MJ, Cushman M, et al. Executive summary: heart disease and stroke statistics-2016 update: a report from the American Heart Association. Circulation. 2016;133(4):447-54.

2. Pressler SJ. Cognitive functioning and chronic heart failure: a review of the literature (2002-July 2007). J Cardiovasc Nurs. 2008;23(3):239-49.

3. Bennett SJ, Sauve MJ. Cognitive deficits in patients with heart failure: a review of the literature. J Cardiovasc Nurs. 2003;18(3):219-42.

4. Petrucci RJ, Truesdell KC, Carter A, Goldstein NE, Russell MM Dilkes D, et al. Cognitive dysfunction in advanced heart failure and prospective cardiac assist device patients. Ann Thorac Surg. 2006;81(5): 1738-44.
5. Mungas D, Reed BR, Kramer JH. Psychometrically matched measures of global cognition, memory, and executive function for assessment of cognitive decline in older persons. Neuropsychology. 2003;17(3):380-92.

6. Vogels RL, Oosterman JM, van Harten B, Scheltens $\mathbf{P}$, van der Flier WM, Schroeder-Tanka JM, et al. Profile of cognitive impairment in chronic heart failure. J Am Geriatr Soc. 2007;55(11):1764-70.

7. Wolters FJ, Zonneveld HI, Hofman A, van derLugt A, Koudstaal PJ, Vernooij MW, et al. Cerebral Perfusion and the Risk of Dementia: A Population-Based Study. Circulation. 2017;136(8):719-28.

8. Arntzen KA, Schirmer H, Johnsen SH, Wilsgaard T, Mathiesen EB. Carotid atherosclerosis predicts lower cognitive test results: a 7-year follow-up study of 4,371 stroke-free subjects - the Tromso study. Cerebrovasc Dis. 2012;33(2):159-65.

9. Yaffe K, Vittinghoff E, Pletcher MJ, Hoang TD, Launer LJ, Whitmer R, et al. Early adult to midlife cardiovascular risk factors and cognitive function. Circulation. 2014;129(15): 1560-7.

10. Reis JP, Launer LJ, Terry JG, Loria CM, Zeki Al Hazzouri A, Sidney S, et al. Subclinical atherosclerotic calcification and cognitive functioning in middle-aged adults: the CARDIA study. Atherosclerosis. 2013;231(1):72-7.

11. Knopman D, Boland LL, Mosley T, Howard G, Liao D, Szklo M, et al. Cardiovascular risk factors and cognitive decline in middle-aged adults. Neurology. 2001;56(1):42-8.

12. Alves de Moraes S, Szklo M, Knopman D, Sato R. The relationship between temporal changes in blood pressure and changes in cognitive function: atherosclerosis risk in communities (ARIC) study. Prev Med. 2002;35(3):258-63.

13. Gottesman RF, Albert MS, Alonso A, Coker LH, Coresh J, Davis SM, et al. Associations Between Midlife Vascular Risk Factors and 25-Year Incident Dementia in the Atherosclerosis Risk in Communities (ARIC) Cohort. JAMA Neurol. 2017;74(10):1246-54.

14. Giao Y, Suri FK, Zhang Y, Liu L, Gottesman R, Alonso A, et al. Racial differences in prevalence and risk for intracranial atherosclerosis in a US community-based population. JAMA Cardiol. 2017;2(12):1341-8.

15. Gottesman RF, Schneider AL, Albert M, Alonso A, Bandeen-Roche $\mathbf{K}$, Coker L, et al. Midlife hypertension and 20-year cognitive change: the atherosclerosis risk in communities neurocognitive study. JAMA Neurol. 2014;71(10):1218-27.

16. Feldman AM, Haller JA, DeKosky ST. Valsartan/sacubitril for heart failure: Reconciling disparities between preclinical and clinical investigations. JAMA. 2016;315(1):25-6.

17. Vogels RL, Scheltens P, Schroeder-Tanka JM, Weinstein HC. Cognitive impairment in heart failure: a systematic review of the literature. Eur J Heart Fail. 2007;9(5):440-9.

18. Mirza SS, de Bruijn RF, Koudstaal PJ, van den Meiracker AH, Franco OH, Hofman A, et al. The N-terminal pro B-type natriuretic peptide, and risk of dementia and cognitive decline: a 10-year follow-up study in the general population. J Neurol Neurosurg Psychiatry. 2016;87(4):356-62.

19. Jefferson AL, Poppas A, Paul RH, Cohen RA. Systemic hypoperfusion is associated with executive dysfunction in geriatric cardiac patients. Neurobiol Aging. 2007;28(3):477-83.

20. Gottesman RF, Grega MA, Bailey MM, Zeger SL, Baumgartner WA McKhann GM, et al. Association between hypotension, low ejection fraction and cognitive performance in cardiac patients. Behav Neurol. 2010;22(1-2):63-71.

21. Kindermann I, Fischer D, Karbach J, Link A, Walenta K, Barth C, et al Cognitive function in patients with decompensated heart failure: the Cognitive Impairment in Heart Failure (CogImpair-HF) study. Eur J Heart Fail. 2012;14(4):404-13.

22. The Atherosclerosis Risk in Communities (ARIC) Study: design and objectives. The ARIC investigators. Am J Epidemiol. 1989;129(4):687702 .

23. Knopman DS, Gottesman RF, Sharrett AR, Wruck LM, Windham BG, Coker L, et al. Mild cognitive impairment and dementia prevalence: The Atherosclerosis Risk in Communities Neurocognitive Study (ARIC-NCS). Alzheimers Dement (Amst). 2016;2:1-11.

24. Schneider AL, Sharrett AR, Gottesman RF, Coresh J, Coker L, Wruck $\mathbf{L}$, et al. Normative data for 8 neuropsychological tests in older blacks and whites from the atherosclerosis risk in communities (ARIC) study. Alzheimer Dis Assoc Disord. 2015;29(1):32-44.

25. Gross AL, Power MC, Albert MS, Deal JA, Gottesman RF, Griswold M, et al. Application of latent variable methods to the study of cognitive decline when tests change over time. Epidemiology. 2015;26(6):878-87.

26. Deal JA, Sharrett AR, Albert MS, Coresh J, Mosley TH, Knopman D, et al. Hearing impairment and cognitive decline: a pilot study conducted within the atherosclerosis risk in communities neurocognitive study. Am J Epidemiol. 2015;181(9):680-90. 
27. Bressler J, Knopman DS, Sharrett AR, Gottesman RF, Penman A Chang PP, et al. Incident heart failure and cognitive decline: the Atherosclerosis Risk in Communities Study. J Card Fail. 2016.

28. Shah AM, Cheng S, Skali H, Wu J, Mangion JR, Kitzman D, et al Rationale and design of a multicenter echocardiographic study to assess the relationship between cardiac structure and function and heart failure risk in a biracial cohort of community-dwelling elderly persons: the Atherosclerosis Risk in Communities study. Circ Cardiovasc Imaging. 2014;7(1):173-81.

29. Shah AM, Claggett B, Loehr LR, Chang PP, Matsushita K, Kitzman D, et al. Heart failure stages among older adults in the community: the Atherosclerosis Risk in Communities Study. Circulation. 2017; 135(3):224-40

30. Rosamond WD, Chang PP, Baggett C, Johnson A, Bertoni AG, Shahar $\mathbf{E}$, et al. Classification of heart failure in the atherosclerosis risk in communities (ARIC) study: a comparison of diagnostic criteria. Circ Heart Fail. 2012;5(2):152-9.

31. Austin SR, Wong YN, Uzzo RG, Beck JR, Egleston BL. Why summary comorbidity measures such as the Charlson Comorbidity Index and Elixhauser Score work. Med Care. 2015;53(9):e65-72.

32. Rosamond WD, Folsom AR, Chambless LE, Wang CH, McGovern PG Howard G, et al. Stroke incidence and survival among middle-aged adults: 9-year follow-up of the Atherosclerosis Risk in Communities (ARIC) cohort. Stroke. 1999;30(4):736-43.

33. White AD, Folsom AR, Chambless LE, Sharret AR, Yang $K$, Conwill $D$ et al. Community surveillance of coronary heart disease in the Atherosclerosis Risk in Communities (ARIC) Study: methods and initial two years' experience. J Clin Epidemiol. 1996;49(2):223-33.

34. Norby FL, Soliman EZ, Chen LY, Bengtson LG, Loehr LR, Agarwal SK, et al. Trajectories of cardiovascular risk factors and incidence of atria fibrillation over a 25-year follow-up: the ARIC Study (Atherosclerosis Risk in Communities). Circulation. 2016;134(8):599-610.

35. Cundiff JM, Smith TW, Uchino BN, Berg CA. Subjective social status: construct validity and associations with psychosocial vulnerability and self-rated health. Int J Behav Med. 2013;20(1):148-58

36. Kohout FJ, Berkman LF, Evans DA, Cornoni-Huntley J. Two shorter forms of the CES-D (Center for Epidemiological Studies Depression) depression symptoms index. J Aging Health. 1993;5(2):179-93.

37. Schein RL, Koenig HG. The Center for Epidemiological StudiesDepression (CES-D) Scale: assessment of depression in the medically ill elderly. Int J Geriatr Psychiatry. 1997;12(4):436-46.

38. Salthouse T. Major issues in cognitive aging. Oxford University Press; 2010.

39. Hayden KM, Reed BR, Manly JJ, Tommet D, Pietrzak RH, Chelune GJ, et al. Cognitive decline in the elderly: an analysis of population heterogeneity. Age and Ageing. 2011;40(6):684-9.

40. Zuccala G, Cattel C, Manes-Gravina E, Di Niro MG, Cocchi A, Bernabei R. Left ventricular dysfunction: a clue to cognitive impairment in older patients with heart failure. J Neurol Neurosurg Psychiatry. 1997;63(4):509-12.

41. Sabayan B, van Buchem MA, Sigurdsson S, Zhang $\mathbf{9}$, Meirelles $\mathbf{O}$, Harris TB, et al. Cardiac and carotid markers link with accelerated brain atrophy: the AGES-Reykjavik Study (age, gene/environment susceptibility-Reykjavik). Arterioscler Thromb Vasc Biol. 2016;36(11):2246-51.

42. Zonneveld HI, Ikram MA, Hofman A, Niessen WJ, van der Lugt A Krestin GP, et al. N-terminal pro-B-type natriuretic peptide and subclinical brain damage in the general population. Radiology. 2017;283(1):20514

43. de Roos A, van der Grond J, Mitchell G, Westenberg J. Magnetic resonance imaging of cardiovascular function and the brain: is dementia a cardiovascular-driven disease? Circulation. 2017;135(22):2178-95.

44. Sabayan B, van Buchem MA, Sigurdsson S, Zhang Q, Harris TB, Gudnason V, et al. Cardiac hemodynamics are linked with structural and functional features of brain aging: the age, gene/environment susceptibility (AGES)-Reykjavik Study. J Am Heart Assoc. 2015;4(1):e001294.

45. Zuccala G, Marzetti E, Cesari M, Lo Monaco MR, Antonica L, Cocchi A, et al. Correlates of cognitive impairment among patients with heart failure: results of a multicenter survey. Am J Med. 2005;118(5):496-502.

46. Hajduk AM, Kiefe CI, Person SD, Gore JG, Saczynski JS. Cognitive change in heart failure: a systematic review. Circ Cardiovasc Qual Outcomes. 2013;6(4):https://doi.org/10.1161/CIRCOUTCOMES.113. 000121.

47. Mirza SS, Ikram MA, Bos D, Mihaescu R, Hofman A, Tiemeier H. Mild cognitive impairment and risk of depression and anxiety: a populationbased study. Alzheimers Dement. 2017;13(2):130-9.

48. Tabue-Teguo M, Grasset L, Avila-Funes JA, Genuer R, Proust-Lima C, Peres $\mathbf{K}$, et al. Prevalence and co-occurrence of geriatric syndromes in people aged 75 years and older in France: results from the Bordeaux Three-city Study. J Gerontol A Biol Sci Med Sci. 2017;73(1):109-16. 